\title{
Atividades e participação de crianças com Paralisia Cerebral conforme a Classificação Internacional de Funcionalidade, Incapacidade e Saúde
}

\author{
Activities and participation of children with Cerebral Palsy according to the \\ International Classification of Functioning, Disability, and Health \\ Actividades y participación de niños com Parálisis Cerebral según la \\ Clasificación Internacional de Funcionalidad, Incapacidad y Salud
}

\section{Ismênia de Carvalho Brasileiro', Thereza Maria Magalhães Moreira", Maria Salete Bessa Jorge e'II, Maria Veraci Oliveira Queiroz", Daniele Gardano Bucharles Mont'Alverne ${ }^{\mathrm{IV}}$ \\ 'Universidade Estadual do Ceará. Mestrado Acadêmico Cuidados Clínicos em Saúde. Fortaleza, CE "Universidade Estadual do Ceará. Mestrado Profissional em Saúde da Criança e do Adolescente, Fortaleza, CE II'Universidade Estadual do Ceará. Mestrado Acadêmico de Saúde Pública. Fortaleza, CE

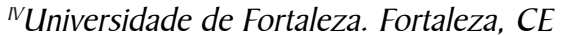

\section{RESUMO}

A paralisia cerebral compromete o desempenho funcional do indivíduo acometido. Entretanto, as alterações nas atividades e participação deste têm sido pouco discutidas na literatura. O objetivo da presente pesquisa foi descrever características de um grupo de crianças com paralisia cerebral de uma instituição de Fortaleza Quanto à capacidade em executar tarefas e participar das atividades de vida diária por meio da Classificação Internacional de Funcionalidade, Incapacidade e Saúde. Ao todo 32 participantes foram avaliados. Os dados foram coletados e agrupados pelo programa Statistical Package of Social of Science. A utilização da CIF proporcionou uma descrição objetiva Quanto à dimensão da limitação das crianças com paralisia cerebral estudadas e Quanto ao impacto desta alteração na vida da criança. Descritores: Paralisia cerebral; Função; Criança; Deficiência.

\section{ABSTRACT}

Cerebral palsy is among the most common motor disabilities in our midst that limits individuals from carrying out their normal daily routines. The adjacent alterations, characterization, and participation of the child in these activities is not appropriated explored in the literature. The objective of this survey was to describe the capacity and performance of the children with cerebral palsy treated at an institution in the city of Fortaleza as to their capacity to carry out tasks and participate in daily life activities as stated in the International Classification of Functioning, Disability, and Health. Thirty-two children were evalueted. The data collected was grouped by the software Statistical Package of Social of Science (SPSS). The ICF had proportioned an objective description from cerebral palsy disabilities. It was clear that the impact that the disease has on the life of the children.

Descriptors: Cerebral palsy; Function; Children; Disability.

\section{RESUMEN}

La parálisis cerebral afecta al desempeño funcional del individuo acometido. Sin embargo, las alteraciones en las actividades y participación de este han sido poco discutidas en la literatura. El objetivo de la presente investigación fue describir características de un grupo de niños con parálisis cerebral de una institución de Fortaleza en relación a la capacidad de ejecutar tareas y participar en actividades de la vida diaria, por medio de la Clasificación Internacional de Funcionalidad, Incapacidad y Salud. En total fueron evaluados 32 participantes. Los datos fueron colectados y agrupados por el programa Statistical Package of Social of Science. La utilización de la CIF proporcionó una descripción objetiva en relación a la dimensión de la limitación de los niños con parálisis cerebral estudiada y al impacto de esta alteración en la vida del niño.

Descriptores: Parálisis cerebral; Función; Niño; Deficiencia. 


\section{INTRODUÇÃO}

O interesse em desenvolver a pesquisa é decorrente da experiência da autora como fisioterapeuta em um núcleo de tratamento e estimulação precoce, Que atende crianças com disfunções neurológicas, incluindo a paralisia cerebral.

Tal estudo é derivado da dissertação de mestrado intitulada Perfil Funcional de crianças com paralisia cerebral em uma instituição de Fortaleza, Ceará, desenvolvida no curso de Mestrado Profissional em Saúde da Criança e do Adolescente, em 2007.

As atuais e constantes transformações sofridas pela área da saúde em seus modelos norteadores de avaliação e reabilitação pressupõem uma concepção de saúde ampliada, considerando-a em um contexto Que integra ambiente, fatores sociais e psicológicos, dentre outros. Isso representa um avanço, pois até a década de 80 do século XX enfocava-se, sobretudo, a doença.

A prevalência de pessoas com algum tipo de deficiência atinge cerca de $10 \%$ da população, constituindo-se Questão de saúde pública. Entre as deficiências existentes, chamam a atenção os casos de paralisia cerebral (PC), por representar a maior incidência entre as crianças Que apresentam incapacidade motora(l)

Essa disfunção motora resulta na incapacidade e limitação do indivíduo em desempenhar atividades e tarefas do seu cotidiano e de sua família. Diversas são as descrições das alterações adjacentes à paralisia cerebral, entretanto, a caracterização das atividades cotidianas e a participação da criança acometida nessas atividades ainda são pouco exploradas na literatura e na avaliação para prática assistencial.

O desempenho funcional de uma criança é diretamente influenciado pelas características dos contextos físico e social ${ }^{(2)}$. Mensurar o impacto Que a doença ocasiona na vida da criança e de sua família tem sido um desafio para os profissionais Que lidam com este paciente. A implicação da limitação funcional parece ser proporcional ao impacto da deficiência na vida desses infantes.

Existem inúmeros aspectos a serem investigados em uma avaliação. Nem sempre é possível ter uma equipe multidisciplinar nos serviços, ou ter modelos unificados de avaliação Que facilitem a compreensão pormenorizada das incapacidades da criança.

A Classificação Internacional de Funcionalidade, Incapacidade e Saúde (CIF), modelo aprovado pela Organização Mundial de Saúde reflete essa mudança de abordagem e prioriza a funcionalidade como componente da saúde enfocada a partir da limitação do paciente e de seu comprometimento em atividades.

A CIF é uma classificação de saúde e de domínios relacionados à saúde. A organização de sua informação é dividida em duas partes, sendo Que cada uma possui dois componentes: a primeira parte contempla áreas de Funcionalidade e Incapacidade, e se subdivide em Funções e Estruturas do Corpo; e Atividades e Participação; e a segunda parte se refere aos Fatores Contextuais e subdivide-se em: Fatores Ambientais e Fatores Pessoais. Cada componente contém vários domínios e em cada domínio existem várias categorias, ou unidades de classificação.

Dentre os aspectos analisados na CIF estão os blocos de Atividades, Que consistem na execução de uma tarefa ou uma ação por uma pessoa, e Participação, Que é o envolvimento de uma pessoa numa situação da vida real. A CIF apresenta uma listagem de atividades, envolvendo a faixa completa das áreas da vida, desde a aprendizagem básica e observação até áreas mais complexas, como as relacionadas com as tarefas sociais ${ }^{(3)}$.

Nesse sentido, o uso da taxonomia consiste em ser um instrumento adequado para evidenciar o impacto das alterações físicas no desempenho das atividades cotidianas da criança. Os achados do presente estudo contribuirão para diagnóstico funcional valorizando aspectos pertinentes às capacidades e desempenho das crianças estudadas frente às atividades cotidianas. Além disso, poderão favorecer a elaboração de plano terapêutico adęuado, com estratégias eficazes junto à criança, família, instituições de saúde, ensino e comunidade, fornecendo subsídios para inclusão escolar e social, visto que o enfoque da CIF é biopsicossocial.

Diante do exposto, o estudo teve como objetivo principal caracterizar as atividades e participação de um grupo de crianças com paralisia cerebral em acompanhamento fisioterapêutico em um núcleo de tratamento e estimulação precoce, em Fortaleza Ceará, por meio da CIF.

\section{METODOLOGIA}

Trata-se de um estudo descritivo-exploratório, o Qual procura descobrir a freqüência com Que o fenômeno ocorre, sua natureza, suas características, causas, relações e conexões com outros fenômenos. A natureza da pesQuisa é, predominantemente, Quantitativa e de estrutura transversal, na Qual todas as variáveis são medidas em um único momento, sem período de acompanhamento $^{(4)}$

O estudo foi desenvolvido no Núcleo de Tratamento e Estimulação Precoce (NUTEP) da Universidade Federal do Ceará. A população alvo consistiu de todas as crianças com paralisia cerebral em tratamento fisioterápico, atendidas duas vezes por semana, totalizando 140 crianças.

Os critérios de inclusão adotados para a amostra foram: ter diagnóstico definitivo de paralisia cerebral; apresentar comprometimento neuromotor leve ou moderado; ter idade a partir de três anos, e manter freqüência ao tratamento. Ao todo, 32 crianças foram selecionadas para participar do estudo. Crianças com déficits sensoriais, como deficiência visual e/ou auditiva incapacitantes, dificuldade de comunicação com o avaliador (retardo mental), crises convulsivas de difícil controle e paralisia cerebral do tipo grave foram excluídas do estudo.

A delimitação da idade é justificada porque é esperado que aos três anos de idade a criança sem alteração tenha adQuirido independência motora, e esteja saindo do seu núcleo familiar para inserção em escola regular, núcleo das primeiras relações sociais.

Dados sócio-demográficos e clínicos foram analisados para contextualizar os participantes no universo da pesquisa. A coleta dos demais dados foi realizada por meio da CIF Que oferece uma estrutura de coleta de dados sobre a dimensão da limitação do paciente e seu comprometimento em atividades e um sistema para a codificação de informações sobre saúde e, em especial, sobre função mediante a deficiência, utilizando uma linguagem comum e padronizada ${ }^{(3)}$.

$\mathrm{Na} \mathrm{CIF}$, a organização da informação é dividida em duas partes, Que possuem dois componentes: a primeira parte contempla áreas de Funcionalidade e Incapacidade, e se subdivide em Funções e Estruturas do Corpo; e Atividades e Participação. Cada componente contém vários domínios e em cada domínio existem várias categorias, ou unidades de classificação. Cada um dos componentes pode ser 
representado tanto em termos positivos como negativos.

Cada categoria é expressa por um código, onde são acrescidos uma ou mais escalas numéricas, denominadas de Qualificadores. Estes são utilizados para descrever a extensão ou a magnitude da funcionalidade ou da incapacidade naQuela categoria eleita para o estudo.

Para análise das limitações de atividades e restrição à participação, foi aplicado o primeiro qualificador da $\mathrm{CIF}^{(3)}$, onde foram analisados itens de Capacidade e Desempenho para executar uma determinada função, tendo como base os itens $0,1,2,3$, e 4, onde 0 significava nenhuma deficiência, I deficiência leve (5-24\%), 2 moderada (2549\%), 3 grave (50-95\%) e, 4 deficiência completa (96-100\%).

O Qualificador de Desempenho descreve o Que a criança realiza no contexto habitual em Que vive. $\mathrm{O}$ Qualificador de Capacidade descreve se a criança é capaz de executar uma tarefa ou ação, identificando o nível máximo provável de funcionamento Que a mesma pode atingir em um dado momento. Existem Quatro opções de utilização dos Qualificadores. Para esse estudo, optou-se pela utilização dos mesmos domínios, tanto para atividades como para participação, em Que cada categoria pôde ser interpretada como funcionalidade individual (atividade) bem como funcionalidade social (participação).

O instrumento foi elaborado de acordo com a descrição da CIF, pela própria examinadora, Quanto à especificidade da população estudada. No momento da pesQuisa não havia sido disponibilizada a CIF para crianças e adolescentes.

O local onde foi aplicado o instrumento foi o serviço de fisioterapia do NUTEP, ambiente adequado, livre de interferências externas, com dia e horários previamente estabelecidos, no período de julho a setembro de 2006. O familiar ou responsável permaneceu na sala durante toda a avaliação.

Os dados foram agrupados pelo programa SPSS versão I6. I com posterior análise e interpretação. A partir das informações coletadas, foram montados Quadros e gráficos descritivos, discutidos com base na literatura. Em todo o processo, contou-se com a assessoria de um estatístico.

O presente protocolo de pesquisa foi desenvolvido seguindo a Resolução $n^{\circ}$. 196 de 10 de outubro de 1996 do Conselho Nacional de Saúde, Que aprovou as diretrizes e normas regulamentadoras de pesquisas envolvendo seres humanos ${ }^{(5)}$.

Os responsáveis pela criança receberam esclarecimentos Quanto à participação no estudo e assinaram um termo de consentimento livre e esclarecido, autorizando a inserção da criança no estudo. Somente participaram as crianças cujos responsáveis expressaram de forma escrita sua anuência.

Aos participantes, foram dadas garantias de anonimato, de não sofrer danos, e foi assegurada a possibilidade de desistir do estudo a Qualeuer momento. A pesQuisa não trouxe QualQuer prejuízo do tipo moral, físico, psíquico ou financeiro aos participantes.

A dissertação que originou o artigo foi aprovada pelo Comitê de Ética em PesQuisa da Universidade Estadual do Ceará e registrada sob o número do protocolo 06093295-3. FR 85646.

\section{RESULTADOS E DISCUSSÃO}

Foi verificado Que a média de faixa etária das crianças estudadas foi de 5,37 anos e o desvio padrão de 1,6 anos. O sexo masculino prevaleceu no estudo com um percentual de 59,4\% $(n=19)$. Com relação à escolaridade, $28,1 \%(n=7)$ das crianças estavam no infantil III, 43,8\% $(n=14)$ no infantil VI e V e, 25\% $(n=8)$ no primeiro ano. Somente uma criança freeüentava escola especial. A perspectiva escolar tem proporcionado essa primeira inserção das crianças especiais na vida em sociedade, embora muito ainda precise ser feito.

A família da maioria das crianças arrecada mensalmente em média dois salários mínimos $(n=23)$, correspondendo a 71,9\% dos casos. Sabe-se que a maior vulnerabilidade para ocorrência de transtornos no desenvolvimento está em famílias de baixo nível sócioeconômico $^{(6)}$.

Nos achados do estudo observou-se que $87,5 \%(n=28)$ das crianças apresentavam paralisia cerebral do tipo espástica. Duas crianças apresentaram ataxia $(6,2 \%)$, e duas, paralisia cerebral mista. Quase metade das crianças estudadas apresentou hemiparesia, sendo Que em $18,7 \%$ dessas o comprometimento foi à direita e em $28,1 \%$ à esquerda. Cerca de $30 \%$ das crianças apresentou diparesia e apenas $1 / 4$ Quadriparesia. De acordo com a literatura, o tipo espástico é predominante nos casos de paralisia cerebral ${ }^{(7-12)}$.

Diversos estudos apontam para o fato Que a paralisia cerebral além da disfunção motora, pode ocasionar demais alterações na função cerebral como anomalias sensoriais visuais e auditivas, cognitivas, sensitivas, corticais, de atenção, vigilância, comportamento e epilepsias Que certamente influenciarão negativamente tanto na aQuisição de conhecimentos, pela interferência do processo receptivo, Quanto nas habilidades de expressar pensamentos por meio de atos motores ${ }^{(13-15)}$. Na avaliação utilizando a CIF vários destes aspectos foram analisados no bloco de atividades sugeridos pela própria taxonomia (Quadro 1).

Foram analisados dados Quanto à capacidade de aprendizagem e aplicação do conhecimento dos participantes. Foi observado Que grande parte das crianças do estudo, 68,7\% $(n=22)$ não tinha dificuldades em utilizar, intencionalmente, os sentidos básicos do corpo para captar estímulos como tocar, sentir texturas, saborear doce ou sentir cheiros.

Verificou-se Que 50\% $(n=16)$ dos infantes apresentaram dificuldades em brincar com objetos, não por incompreensão, mas devido às interferências motoras impostas pela PC.

Quanto à capacidade em utilizar palavras, frases ou sentenças foram visto Que $34,3 \%(n=11)$ das crianças tiveram dificuldades leves, 12,5\% $(n=4)$ apresentaram dificuldade moderada, dois casos apresentaram grave deficiência em executar a fala no contexto habitual e social, e uma criança apresentou deficiência completa na produção da fala.

A criança com paralisia cerebral pode apresentar alteração na produção de fala, desde leve transtorno articulatório até disartria de grau severo, com ausência completa de inteligibilidade de fala, não sendo a gravidade da lesão diretamente proporcional às conseQüências, pois casos mais leves podem apresentar problemas de fala bem mais acentuados, Que os mais graves ${ }^{(15)}$.

Um recente estudo sobre paralisia cerebral diplégica espástica apontou uma correlação estatística significante entre o grau de distúrbio motor e o desempenho psicolingüístico ${ }^{(16)}$. No presente estudo foi observado Que cerca de $30 \%$ dos casos são diplégicas e Que consequentemente estão associadas às estatísticas de casos com distúrbios de linguagem.

Cerca de 50\% do grupo de crianças apresentou dificuldades em 


\begin{tabular}{|c|c|c|c|c|c|c|c|c|c|c|}
\hline \multirow{2}{*}{$\begin{array}{l}\text { ATIVIDADES E PARTICIPAÇÃO } \\
\text { APRENDIZAGEM E APLICAÇÃO DO CONHECIMENTO }\end{array}$} & \multicolumn{5}{|c|}{ Desempenho } & \multicolumn{5}{|c|}{ Capacidade } \\
\hline & 0 & 1 & 2 & 3 & 4 & 0 & I & 2 & 3 & 4 \\
\hline Dificuldades em tocar, sentir texturas, saborear ou sentir cheiros & 22 & 8 & 2 & & & 22 & 8 & 2 & & \\
\hline Dificuldade em brincar com objetos & 9 & 16 & 7 & & & 9 & 15 & 8 & & \\
\hline Dificuldades em usar palavras, frases ou sentenças & 14 & 11 & 4 & 2 & I & 14 & 11 & 4 & 2 & I \\
\hline Dificuldades com conceitos como Quantidade, comprimento, igual ou diferente & 16 & 8 & 5 & 3 & & 16 & 8 & 5 & 3 & \\
\hline Dificuldades de aprendizagem para ler & & 3 & 2 & 2 & 25 & & 3 & 2 & 2 & 25 \\
\hline Dificuldades de aprendizagem para escrever & & 2 & 4 & 4 & 22 & & 2 & 4 & 4 & 22 \\
\hline Dificuldades de aprendizagem para calcular & & 2 & & 5 & 25 & & 2 & & 5 & 25 \\
\hline Dificuldades de concentração & 4 & 18 & 10 & & & 4 & 19 & 9 & & \\
\hline TAREFAS GERAIS E DEMANDAS & & & & & & & & & & \\
\hline Realizar uma única tarefa ou responder a uma única comunicação & 20 & 9 & 2 & 1 & & 20 & 9 & 2 & 1 & \\
\hline $\begin{array}{l}\text { Dificuldades em seguir as exigências dos deveres do dia-a-dia } \\
\text { COMUNICAÇÃO }\end{array}$ & 7 & 18 & 6 & 1 & & 7 & 18 & 6 & I & \\
\hline Dificuldade em entender o que os outros dizem & 18 & 13 & 1 & & & 18 & 13 & 1 & & \\
\hline Dificuldade em entender o significado de gestos ou figuras & 19 & 11 & 2 & & & 19 & 11 & 2 & & \\
\hline Dificuldades na produção da fala & 9 & 13 & 6 & 3 & 1 & 9 & 13 & 6 & 3 & I \\
\hline Dificuldades em utilizar gestos, símbolos, ou desenhos para se comunicar & 19 & 6 & 7 & & & 19 & 6 & 7 & & \\
\hline MOBILIDADE & & & & & & & & & & \\
\hline MUDAR E MANTER A POSIÇÃO DO CORPO & & & & & & & & & & \\
\hline Mudar a posição básica do corpo & 4 & 11 & 13 & 4 & & 4 & 11 & 13 & 4 & \\
\hline Deitar & 9 & 19 & 2 & 2 & & 9 & 19 & 1 & 3 & \\
\hline Agachar & 1 & 8 & 10 & 11 & 2 & I & 8 & 9 & 12 & 2 \\
\hline Ajoelhar & 5 & 10 & 13 & 3 & 1 & 5 & 10 & 13 & 3 & 1 \\
\hline Sentar & 1 & 17 & 7 & 5 & 2 & 1 & 17 & 7 & 5 & 2 \\
\hline AQuisição da postura de pé & 2 & 12 & 12 & 5 & 1 & 2 & 12 & 11 & 6 & 1 \\
\hline Curvar & 3 & 12 & 11 & 6 & & 3 & 12 & 10 & 7 & \\
\hline Mudar o centro de gravidade do corpo & 3 & 10 & 15 & 4 & & 3 & 10 & 14 & 5 & \\
\hline Manter a posição do corpo & 9 & 13 & 8 & 2 & & 9 & 13 & 7 & 3 & \\
\hline Deitado & 18 & 12 & 2 & & & 18 & 12 & 2 & & \\
\hline Agachado & 1 & 10 & 8 & 8 & 4 & 1 & 10 & 7 & 9 & 5 \\
\hline Ajoelhado & 7 & 9 & 8 & 6 & 2 & 7 & 9 & 7 & 7 & 2 \\
\hline Sentado & 10 & 11 & 11 & & & 10 & 11 & 11 & & \\
\hline De pé & 8 & 9 & 10 & 5 & & 8 & 9 & 10 & 4 & 1 \\
\hline Auto-transferências & 7 & 10 & 11 & 3 & 1 & 7 & 10 & 11 & 3 & 1 \\
\hline Na posição de sentado & 7 & 9 & 12 & 2 & 2 & 7 & 9 & 12 & 2 & 2 \\
\hline Na posição de deitado & 8 & 13 & 7 & 4 & & 8 & 13 & 7 & 4 & \\
\hline TRANSPORTAR, MOVER E MANUSEAR OBJETOS & & & & & & & & & & \\
\hline Levantar e transportar objetos & 9 & 14 & 7 & 12 & & 9 & 14 & 7 & 12 & \\
\hline Levantar objetos & 10 & 12 & 8 & 8 & & 10 & 12 & 8 & 8 & \\
\hline Transportar nas mãos & 14 & 8 & 7 & 3 & & 14 & 8 & 6 & 4 & \\
\hline Colocar objetos no chão & 11 & 9 & 8 & 3 & 1 & 11 & 9 & 7 & 4 & 1 \\
\hline Mover objetos com os membros inferiores & 11 & 10 & 8 & 3 & & 11 & 10 & 7 & 4 & \\
\hline Empurrar objeto com os membros inferiores & 13 & 8 & 8 & 3 & & 13 & 8 & 8 & 2 & 1 \\
\hline Chutar algo para longe & 8 & 11 & 8 & 3 & 2 & 8 & 11 & 8 & 2 & 3 \\
\hline Movimentos finos da mão & 6 & 15 & 8 & 3 & & 6 & 15 & 7 & 4 & \\
\hline Pegar objeto pequeno como um lápis com as mãos e dedos & 6 & 21 & 2 & 3 & & 6 & 20 & 3 & 3 & \\
\hline Agarrar e segurar com uma ou ambas as mãos ferramenta/maçaneta & 8 & 17 & 3 & 4 & & 8 & 17 & 2 & 4 & I \\
\hline Manipular,controlar, dirigir ou guiar um objeto como moeda & 5 & 15 & 11 & 1 & & 5 & 14 & 12 & 1 & \\
\hline Soltar um objeto de maneira Que ele caia ou mude de posição & 4 & 18 & 9 & 1 & & 4 & 18 & 9 & 1 & \\
\hline Utilização da mão e do braço & 4 & 20 & 8 & & & 4 & 19 & 1 & 8 & \\
\hline Puxar & 6 & 18 & 8 & & & 6 & 18 & 8 & & \\
\hline Empurrar & 6 & 20 & 5 & 1 & & 6 & 20 & 5 & 1 & \\
\hline Alcançar & 7 & 19 & 5 & 1 & & 7 & 19 & 5 & 1 & \\
\hline Girar ou dobrar um objeto usando dedos e mãos & 6 & 15 & 8 & 3 & & 6 & 15 & 8 & 3 & \\
\hline logar & 5 & 18 & 8 & 1 & & 5 & 18 & 8 & 1 & \\
\hline Apanhar ou agarrar bola & 3 & 14 & 11 & 4 & & 3 & 14 & 11 & 4 & \\
\hline
\end{tabular}

Quadro 1. FreQüência das Atividades e Participação de crianças com PC. Fortaleza, 2006.

interpretar conceitos como Quantidade, comprimento, igual e diferente, noção de cor. Dados denotam Que as crianças encontramse fora de faixa Quando se faz uma correlacção entre a idade e o nível de escolaridade. A incapacidade apresentada foi leve em 25\% $(n=8)$ dos casos, moderada em $15,6 \%(n=5)$ e grave em $9,3 \%$ $(n=3)$.
As crianças Que teriam idade cronológica para aQuisição de leitura e cálculo apresentaram dificuldades significativas. Embora com o ato de escrever iniciado, pôde ser observado que a grande maioria dos casos (12,5\% graves $(n=4)$ e $68,7 \%(n=22)$ completas), apresentou dificuldades importantes. Acredita-se Que o déficit não seja puramente motor, como também de aprendizado. 


\begin{tabular}{|c|c|c|c|c|c|c|c|c|c|c|}
\hline \multirow{3}{*}{$\begin{array}{l}\text { ATIVIDADES E PARTICIPAÇÃO } \\
\text { ANDAR E DESLOCAR-SE }\end{array}$} & \multicolumn{5}{|c|}{ Desempenho } & \multicolumn{5}{|c|}{ Capacidade } \\
\hline & 0 & 1 & 2 & 3 & 4 & 0 & 1 & 2 & 3 & 4 \\
\hline & & & & & & & & & & \\
\hline Andar & 4 & 11 & 9 & 1 & 7 & 4 & 11 & 9 & 1 & 7 \\
\hline Andar distâncias curtas (menos de 1 km, como dentro de casa) & 8 & 10 & 6 & 1 & 7 & 8 & 6 & 10 & I & 7 \\
\hline Andar distâncias longas (mais de 1 km em espaços abertos) & 6 & 7 & 8 & 2 & 9 & 6 & 7 & 8 & 2 & 9 \\
\hline Andar sobre superfícies diferentes (inclinadas, irregular, ou móvel) & 2 & 11 & 9 & 3 & 7 & 2 & 11 & 9 & 3 & 7 \\
\hline Andar contornando obstáculos & 2 & 11 & 10 & 2 & 7 & 2 & 11 & 10 & 2 & 7 \\
\hline Deslocar-se & 4 & 12 & 12 & 4 & & 4 & 12 & 11 & 4 & 1 \\
\hline Engatinhar & 2 & 10 & 13 & 5 & 2 & 2 & 10 & 13 & 5 & 2 \\
\hline Subir/descer degraus, meio-fio & 2 & 7 & 12 & 6 & 5 & 2 & 7 & 12 & 6 & 5 \\
\hline Correr & 1 & 8 & 11 & 2 & 10 & 1 & 8 & 11 & 2 & 10 \\
\hline Saltar & 1 & 6 & 9 & 3 & 13 & 1 & 6 & 9 & 3 & 13 \\
\hline Deslocar-se por diferentes locais & 4 & 14 & 8 & 4 & 2 & 4 & 14 & 7 & 5 & 2 \\
\hline Deslocar-se dentro de casa, como entre cômodos & 12 & 7 & 10 & & 3 & 12 & 7 & 10 & & 3 \\
\hline Deslocar-se dentro de edifícios Que não a própria casa & 8 & 11 & 4 & 6 & 3 & 8 & 11 & 4 & 6 & 3 \\
\hline Deslocar-se fora da sua casa e de outros edifícios & 6 & 8 & 9 & 4 & 5 & 6 & 8 & 9 & 4 & 5 \\
\hline Desloca-se utilizando algum tipo de equipamento & 21 & & 4 & 6 & 1 & 21 & & 4 & 6 & 1 \\
\hline \multicolumn{11}{|l|}{ AUTO-CUIDADO } \\
\hline Dificuldades em se lavar & 9 & 12 & 5 & 5 & 1 & 9 & 11 & 6 & 5 & 1 \\
\hline Planejar e executar a eliminação da excreção e posterior limpeza & 7 & 10 & 11 & 3 & 1 & 7 & 9 & 11 & 3 & 2 \\
\hline Vestir e tirar roupas e sapatos & 1 & 9 & 17 & 4 & 1 & 1 & 8 & 17 & 5 & 1 \\
\hline Dificuldades para comer & 8 & 15 & 9 & & & 8 & 15 & 9 & & \\
\hline Cuidados em evitar dano a si próprio & 7 & 1 & 8 & 2 & 4 & 7 & 11 & 8 & 2 & 4 \\
\hline $\begin{array}{l}\text { VIDA DOMÉSTICA: Auxiliar/ participar de alguma atividade doméstica } \\
\text { RELAÇÕES E INTERAÇÕES INTERPESSOAL }\end{array}$ & 17 & 8 & 4 & & 3 & 17 & 8 & 4 & & 3 \\
\hline Interagir com pessoas de modo contextual e socialmente adequado & 12 & 11 & 3 & 2 & 4 & 12 & 11 & 3 & 2 & 4 \\
\hline \multicolumn{11}{|l|}{ ÁREAS PRINCIPAIS DA VIDA } \\
\hline Dificuldades em brincar com os outros & 21 & 8 & 3 & & & 21 & 8 & 3 & & \\
\hline Dificuldades em participar na educação pré-escolar & 11 & 16 & 5 & & & 11 & 14 & 7 & & \\
\hline Dificuldade em obter livre acesso à escola e de participar das atividades & 12 & 9 & 6 & 5 & & 12 & 9 & 6 & 5 & \\
\hline Participar de Qualquer forma de transação econômica simples & 26 & 6 & & & & 26 & 6 & & & \\
\hline \multicolumn{11}{|l|}{ COMUNIDADE, VIDA SOCIAL E CÍVICA } \\
\hline Participar de todos os aspectos da vida social comunitária & 11 & 9 & 9 & 2 & 1 & 11 & 8 & 10 & 2 & 1 \\
\hline Participar de atividades de recreação e lazer satisfatórios & 4 & 13 & 9 & 4 & 2 & 4 & 13 & 9 & 4 & 2 \\
\hline Participar de atividades ou organizações religiosas & 5 & 7 & 19 & & 1 & 5 & 7 & 19 & 1 & \\
\hline
\end{tabular}

Legenda: O (nenhuma dificuldade), I (dificuldade leve), 2 (dificuldade moderada), 3 (dificuldade grave), 4 (dificuldade completa).

Muitas mães relataram Que seus filhos eram dispersos e tinham dificuldades de concentração e atenção Quando solicitados em algumas tarefas. Tais déficits de concentração foram mencionados como de natureza leve em $56,2 \%(n=18)$ e moderada em $31,2 \%$ $(n=10)$.

No bloco Quanto às tarefas gerais e demandas, foi observado Que grande parte das crianças, 62,5\% $(n=20)$, atendia a tarefas e a solicitações simples variando apenas Quanto ao grau de independência motora. Aqueles com alterações mais leves tinham capacidade em atender e em executar, inclusive, a ordens mais complexas de atividades de rotina diária. Cerca de $80 \%(n=25)$, entretanto, apresentou dificuldades em seguir as exigências dos deveres do dia-a-dia, como por exemplo, acordar cedo para ir à escola e tomar banho, dentre outras.

Quanto à comunicação, mais da metade ou $56,2 \%(n=18)$ não apresentou dificuldades em compreender o que os outros diziam. Dentre as dificuldades de comunicação apontadas evidenciou-se a inabilidade em expressarem-se por meio da fala, conforme exposto anteriormente.

A paralisia cerebral implica em incapacidade motora. Conhecer as possibilidades de deslocamento e mobilidade dessas crianças tem significativa importância para seus familiares, cuidadores e escola, bem como para terapeutas membros da equipe de reabilitação Que acompanham tais infantes.

No bloco de mobilidade puderam-se detectar aspectos Quanto ao impacto dessa disfunção motora. $\mathrm{O}$ grupo em estudo foi avaliado no Que diz respeito à capacidade em mudar e manter a posição básica do corpo e em realizar auto-transferências.

O termo mudar significa para CIF adotar e abandonar uma posição corporal e mover-se de um local para outro, como levantarse de uma cadeira para deitar-se na cama e adotar e abandonar posições como ajoelhado e agachado. Manter a posição do corpo significa na CIF manter o corpo na mesma posição durante um determinado período de tempo, como permanecer sentado ou de pé na escola. Transferir a própria posição significa mover-se de uma superfície para outra, como mover-se da cama para cadeira, sem mudar a posição do $\operatorname{corpo}^{(3)}$.

No gráfico I, estão representadas as dificuldades das crianças para mudança de posição. Deitar foi a variável de menor dificuldade, embora, cerca de $60 \%(n=19)$ das crianças ainda tenham apresentado incapacidade leve para realização dessa mudança. As solicitações para mudanças de postura partiram da posição inicial 
sentada. O desempenho para aQuisição da postura foi analisado pelos Qualificadores, tendo ou não dificuldades em assumir a posição. Para esse teste não foi levado em consideração à forma pela Qual assumiram a posição, se utilizaram apoio ou não.

Somente uma criança do grupo conseguiu agachar-se sem apoio. As demais realizaram essa mudança com dificuldade leve $25 \%$ $(n=8)$, moderada $31,2 \%(n=10)$, e grave $34,3 \%(n=11)$. Muitas necessitaram apoiar-se nas mãos para executar o movimento, devido à instabilidade postural e à alteração estrutural da região dos membros inferiores, por rotação interna de Quadril, ou por postura de pé em ponta, impedindo o contato da planta do pé no solo. Duas crianças Quadriparéticas não conseguiram assumir a posição em virtude do grau de acometimento.

Ajoelhar-se também foi uma tarefa difícil para crianças com paralisia cerebral, mesmo para aQueles com disfunções leves. Os dados obtidos demonstraram Que todas as crianças do estudo (100\%) tiveram incapacidade de assumir essa posição, sendo Que em 40,6\% $(n=13)$ a dificuldade foi moderada.

Tais mudanças puderam ser realizadas por crianças Que não deambulavam de forma independente e por aquelas não familiarizadas em desempenhar atividades o chão, somente em tatame. Embora tivessem capacidade para tal, o desempenho foi insatisfatório Quando a solicitação para mudança de postura era feita fora de seu contexto habitual.

Sentar com retidão representa um marco importante nas etapas do desenvolvimento da criança na cultura ocidental. Este permite ficar mais próximo dos adultos, olhar ao redor de si e praticar facilmente atividades manuais ${ }^{(13,17)}$. O processo educativo e de sociabilização da criança se entrelaçam com a aQuisição da postura sentada.

Em $21,8 \%$ dos casos $(n=7)$ as dificuldades para sentar eram moderadas, e em 15,6\% $(n=5)$ graves; $6,2 \%(n=2)$ não conseguiram assumir a posição sentada sozinhos, embora mantivessem controle de tronco Quando colocados nesta postura. Foi observado Que os hemiparéticos tinham preferência em sentar com um membro inferior rodado internamente e o outro rodado externamente. Os paraparéticos, por sua vez, sentaram com maior freqüência em cima das pernas ou em postura " $W$ ", conforme descrito na literatura ${ }^{(7,11,12)}$

A criança com disfunção neuromotora passa boa parte do tempo em posturas fixas e isso acarreta constantes anomalias posturais. EnQuanto crianças normais assumem diferentes modos de sentar, as Quais demarcam sua evolução motora funcional, as com PC só as adQuirem em função de suas possibilidades ${ }^{(17)}$. Estas têm escolhas mais limitadas e tendências mais comuns, tais como as posturas observadas no presente estudo. Embora o sentar irregular promova mais estabilidade e manutenção na postura, para crianças com disfunção, este pode acarretar conseqüências osteoarticulares compensatórias em sua estrutura física.

Adotar a posição de bipedestação também foi uma tarefa difícil em Quase a totalidade das crianças, 84,3\% $(n=27)$. Embora conseguissem esta façanha, muitos a fizeram à custa de grandes esforços. A incapacidade para bipedestação esteve diretamente relacionada ao grau de comprometimento da criança.

As auto-transferências são aQuisições Que as crianças com PC não realizam com muita facilidade. Cerca de $78,1 \%(n=25)$ apresentou incapacidade para transferir-se de uma posição a outra, a partir da posição sentada e $75 \%(n=24)$ dos casos a partir da posição deitada.

$\mathrm{Na}$ avaliação Quanto à capacidade para transportar, mover e manusear objetos verificou-se Que $43,7 \%(n=14)$ dos casos não expressaram dificuldades para transportar objetos nas mãos. Esses dados coincidiram com os casos mais leves de PC, nas Quais 25\% $(n=8)$ tinham dificuldades leves, $21,8 \%(n=7)$ moderadas e $9,3 \%$ $(n=3)$ graves. Nos casos moderados e graves, as crianças foram capazes de transportar e mover objetos, apenas Quando eram transportadas no colo, ou seja, dependiam do auxílio de outra pessoa para desempenhar o teste.

As deficiências de preensão são freqüentes e refletem dificuldades para coordenar cronologicamente os atos de pegar e soltar, coordenar ação de músculos extensores do punho e flexores dos dedos durante a preensão e manipulação, bem como de adaptar a força muscular à carga imposta ${ }^{(8,11,12)}$.

Durante a verificação das atividades motoras finas, observouse Que grande parte, $65,6 \%(n=21)$, apresentou deficiência leve na execução de habilidades mais refinadas como o segurar um lápis

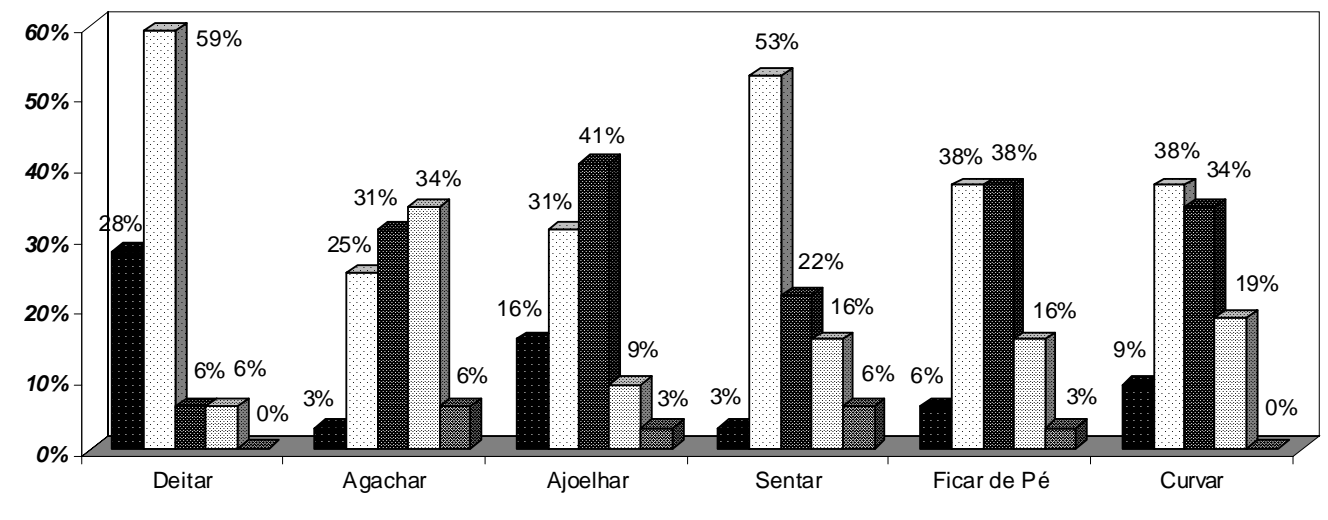

国 Nenhuma Dificuldade $\square$ Dificuldade Leve 娄Dificuldade Moderada 중 Dificuldade Grave 圈 Dificuldade Completa

\section{Gráfico 1. Representação percentual segundo a capacidade e o desempenho das crianças para} mudança da posição básica do corpo. 
ou mover uma maçaneta da porta. Manipular objetos, como moeda, implicou em uma dificuldade leve em $46,2 \%(n=15)$ dos casos e moderada em $34,3 \%(n=11)$.

Atividades Que requeriam amplitude de movimento livre, certa coordenação, eficiência, força e destreza dos movimentos, como puxar, empurrar algo, alcançar, dobrar objetos com as mãos e dedos, jogar e agarrar bola foram analisadas e percebeu-se Que grande parte das crianças, $62,5 \%(n=21)$, apresentou dificuldades leves em executar tais funções.

No bloco de marcha, foi visto Que, Quanto mais elaborada a prova, mais se evidenciavam as incapacidades das crianças. Em $25 \%(n=8)$ dos casos, observou-se Que as crianças eram capazes de andar dentro de casa, com ou sem dispositivo de assistência, somente $18,7 \%(n=6)$, andavam mais de $1 \mathrm{~km}$ em espaços abertos e duas crianças andavam sobre diferentes superfícies e contornavam obstáculos sem dificuldades. Os demais tinham déficits no contexto habitual e social conforme apresentado no gráfico 2 .

Quanto à capacidade de deslocamento, Que para CIF significa mover o corpo inteiro sem ser andando, observou-se em escala negativa Que Quase a totalidade das crianças, 90.7\% $(n=27)$, apresentou dificuldades para deslocar-se, Quer utilizando o engatinhar, ou Quando tem à frente um degrau para subir e descer, ou um meio fio. Foi observada também a incapacidade pronunciada para corrida e salto.

A forma como a criança deslocava-se em diferentes locais foi observada. Um aspecto positivo da escala foi Que 37,5\% $(n=12)$ das crianças não apresentaram dificuldades em deslocar-se dentro de casa. Quando essa criança saía do seu contexto habitual, passava a deparar-se com as barreiras arQuitetônicas existentes a partir da calçada de seu lar. Foi observado Que as Que ainda não sofreram influências do ambiente externo foram exatamente aquelas que necessitavam ser transportados no colo do adulto, ou seja, não desempenhavam deslocamentos sozinhos fora do domicílio. Cerca de $65,6 \%(n=25)$ dos participantes necessitavam utilizar equipamentos para deslocamento.

Embora a condição da criança com PC resulte em alterações neuromotoras de certo modo previsíveis, o desempenho funcional sofre influências tanto intrínsecas como de demandas específicas de cada tarefa, e das próprias características do ambiente no Qual a criança interage $\mathrm{e}^{(19)}$.

Verificou-se Que, para as atividades de auto cuidado, 37,5\% $(n=12)$ tiveram dificuldades leves em se lavar e 34,3\% $(n=11)$ tinham mais defasagem. Poucos eram os Que planejavam e executavam a eliminação da excreção e posterior limpeza 15,6\% (n=5).

Vestir e tirar roupas e sapatos também pareceu ser uma atividade pouco desempenhada por essas crianças. Apenas uma criança não apresentou dificuldade em despir-se ou vestir-se. Cerca de 30\% $(n=10)$ o desempenhava a função com graus leves de dificuldade, mais da metade com moderada incapacidade e $12,5 \%(n=4)$ com Quase total dependência. Cerca de $25 \%(n=8)$ das crianças eram capazes de comer sozinhas e $46,8 \%(n=15)$ o fazem com leve dificuldade.

A paralisia cerebral interfere na interação da criança em contextos relevantes da vida. A influência vai além dos efeitos deletérios no desenvolvimento das atividades motoras globais e finas, estendendose para as atividades de rotina diária, assim como vestimenta, alimentação, banho ${ }^{(20)}$, conforme observado neste estudo.

Sabe-se, entretanto Que as atitudes e expectativas dos pais e cuidadores da criança com PC exercem muitas vezes influências negativas sobre sua independência funcional.

$\mathrm{O}$ desempenho de atividades funcionais em crianças com desenvolvimento normal e crianças com PC foram comparados em um estudo ${ }^{(21)}$, e foi visto Que, dentre outros aspectos, os valores culturais exercem influência no desenvolvimento infantil.

No Brasil, existe uma tendência ao protecionismo em relação às crianças na realização das tarefas da rotina diária. No caso de crianças com PC, existe todo um empenho da equipe multidisciplinar em orientar e estimular sua independência e autonomia funcional ${ }^{(21)}$.

As crianças desse estudo foram analisadas em relação à

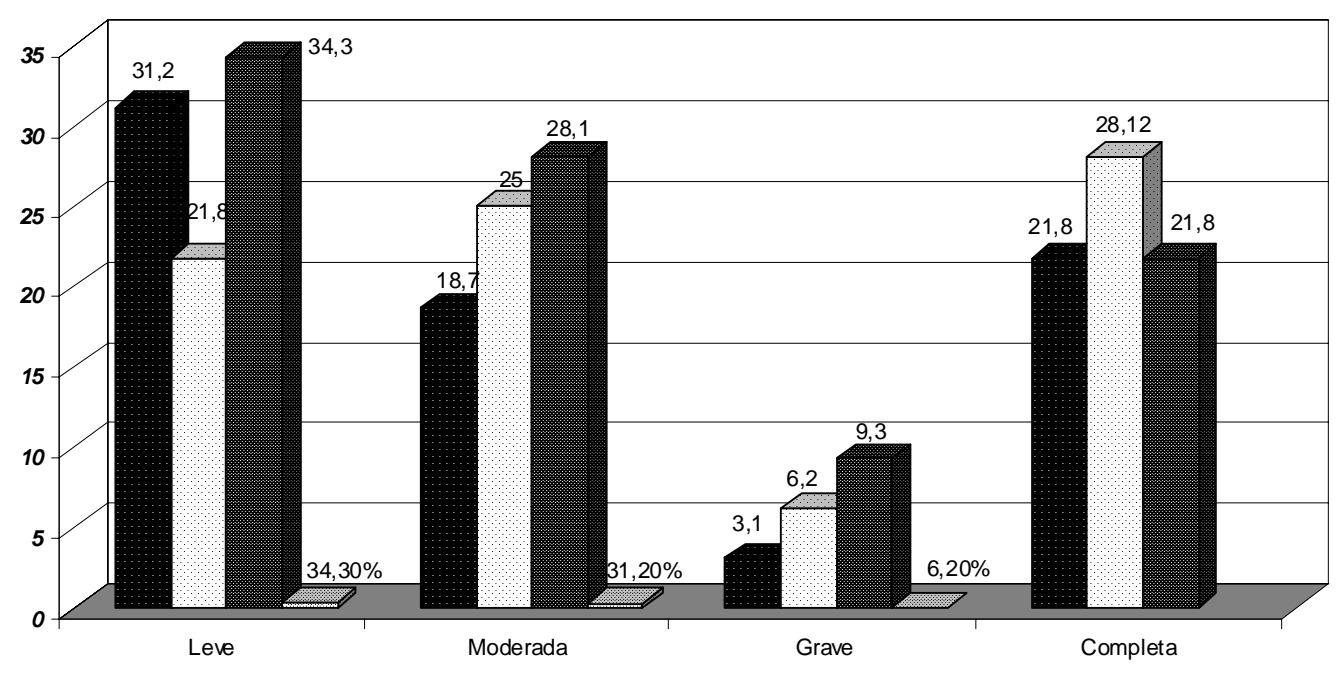

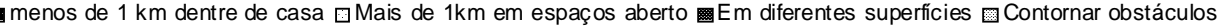

Gráfico 2. Qualidade da marcha em diferentes contextos. 
participação em alguma tarefa doméstica e viu-se Que mais da metade, $52,7 \%(n=17)$ não auxilia em tarefas, mesmo Que consideradas simples como guardar utensílios solicitados pela mãe.

De acordo com o bloco de capacidade para interagir com outras pessoas de modo contextual e socialmente adequado, observou-se Que boa parte, 71,3\% $(n=23)$ das crianças é satisfatoriamente sociável. Acredita-se Que o fato de ter Que sair mais cedo do núcleo familiar e interagir com profissionais de saúde, instituições de tratamento, entre outros, possa influenciar positivamente para o amadurecimento dessa interação.

Nas principais áreas da vida, as crianças não esboçaram, em sua maioria, $89,9 \%(n=29)$ dificuldades em brincar com os outros, nem em participar da educação regular, ou em obter acesso livre à escola e participar das atividades, provavelmente, terem ingressado em tempo adequado em instituições de ensino, e devido famílias e escola ter receberem orientação acerca do processo de desenvolvimento desses infantes.

A grande maioria das crianças, $81,2 \%(n=26)$, não participava de nenhuma forma transação econômica simples. A maioria das crianças, $65,6 \%(n=21)$, participava dos aspectos da vida social comunitária. $\mathrm{O}$ interveniente são as barreiras arquitetônicas, o peso da criança, pois Quase a totalidade das famílias não possui meio de transporte privado e transportá-la torna-se, por vezes, barreira social.

A recreação e o lazer também foram itens esboçados como deficitários, talvez em decorrência do baixo poder aquisitivo dos familiares e, em contra partida, devido aos locais habitacionais não dispuserem de locais adaptados para essa prática social.

Cerca de $84,3 \%(n=27)$, freeüentava alguma instituição religiosa, o Que provavelmente promove melhoria na interação social.

Conhecer as atividades de lazer das crianças auxilia na identificação de aspectos Que pressupõem melhoria nas terapêuticas realizadas, benefícios Quanto ao desenvolvimento da habilidade social de crianças, visto Que ser proporcionado maior participação em atividades de lazer e promove-se uma vasta diversidade de experiências ${ }^{(10)}$.

\section{CONCLUSÃO}

O estudo concluiu Que: crianças com paralisia cerebral espástica leve e moderada apresentam graus de comprometimentos variáveis Quanto às atividades funcionais e participações sugeridas pela Classificação de Funcionalidade, Incapacidade e Saúde.

As alterações adjacentes à disfunção motora Quanto à aprendizagem e aplicação do conhecimento foram evidenciadas nesta peseuisa pela dificuldade em brincar, correlacionada ao comprometimento motor; inaptidão para interpretar conceitos, dificuldades importantes de leitura e escrita, incompatíveis com a idade e déficits de atenção e concentração.

As atividades gerais e demandas são pouco prejudicadas variando apenas de acordo com o grau de independência motora da criança. Quanto à comunicação detectou-se principalmente inabilidade na produção da fala.

O impacto da disfunção passa a ser mais significativo nas atividades Que exigem mudança e manutenção da posição do corpo no espaço. Auto-transferências são tarefas desempenhadas com dificuldade pelo grupo em estudo, mas os déficits em atividades manuais finas são leves.

Um pequeno percentual de casos é capaz de andar dentro de casa, com ou sem dispositivo de assistência, e destes, poucos deambulam em espaços abertos ou sobre diferentes superfícies. As barreiras arQuitetônicas enfrentadas por estes deambuladores são fatores intervenientes para deslocamento mais independente, evidenciando Que o desempenho funcional sofre influências do ambiente no Qual a criança habita. Atividades de vida diária sofrem inteferências negativas.

Acredita-se que por se ausentarem mais precocemente da família essas crianças interajam com outras pessoas de modo contextual e socialmente adequado.

A utilização da CIF proporcionou uma descrição objetiva Quanto à dimensão da limitação e capacidades funcionais das crianças com paralisia cerebral estudadas.

\section{REFERÊNCIAS}

I. Martin MC, Jauregui MVG, Lopez MLS. Incapacidade motora - orientações para adaptar à escola. Porto Alegre: Artmed; 2004.

2. Mancini MC. Gravidade da paralisia cerebral e desempenho funcional. Rev Bras Fisioter 2004; 8(3): 253-60.

3. Organização Mundial de Saúde. Classificação Internacional de Funcionalidade, Incapacidade e Saúde. São Paulo: Centro Colaborador da Organização Mundial de Saúde para a Família das Classificações Internacionais; 2003.

4. Hulley SB, Cummingns SR, Browner WS. Delineando a pesquisa clínica: uma abordagem epidemiológica. $2^{\mathrm{a}}$ ed. Porto Alegre: Artmed; 2003.

5. Ministério da Saúde (BR). Conselho Nacional de Saúde. Aprova Diretrizes e normas regulamentadoras de pesquisas envolvendo seres humanos. Diário Oficial da União 1996 out 16; 201: 21082.

6. Barros KM. Do environmental influences alter motor abilities aceuisition? A comparison among children from day-care centers and private schools. Are Neuropsiquiatr 2003; 61 (2): 170-5
7. Bobath K. Uma base neurofisiológica para o tratamento da paralisia cerebral. $2^{\text {a }}$ ed. São Paulo: Manole; 1998.

8. Diament A, Cypel S. Neurologia infantil. $4^{\mathrm{a}}$ ed. São Paulo: Atheneu: 2006.

9. Lianza S. Análise epidemiológica do consenso nacional sobre espasticidade. 2001. [citado em 29 ago 2006]. Disponível em: http://www.amlar-rehab.com/trabajos.htm.

10. Tecklin IS. Fisioterapia pediátrica. $3^{\text {a }}$ ed. Porto Alegre: Artmed: 2002.

1 1. Shepherd RB. Fisioterapia em pediatria. $3^{\mathrm{a}}$ ed. São Paulo: Santos; 1996.

12. Nelson CA. Paralisia Cerebral. In: Umphred DA. Fisioterapia neurológica. $3^{\text {a }}$ ed. São Paulo: Manole; 2003.

13. Souza AMC, organizador. A criança especial: temas médicos, educativos e sociais. São Paulo: Rocca; 2003.

14. Miller G. Paralisia cerebral: uma visão geral. In: Miller G, Clark G, organizadores. Paralisia cerebral: causas, conseeüências e condutas. São Paulo: Manole; 2002. p. I-4l. 
15. Shapiro BK. Cerebral palsy: a reconceptualization of the spectrum. J Pediatr. 2004; $145(2$ suppl): S3-7.

16. Lamônica DAC, Ferraz PMD. Leucomalácia periventricular e diplegia espástica: implicações nas habilidades psicolingüísticas. Pró-Fono Rev Atual Cien 2007; 19(4).

17. Métayer ML. Reeducação cerebromotora da criança. Educação terapêutica. $2^{\text {a }}$ ed. São Paulo: Santos, 2001.
18. Cardona-Martín M. Incapacidade motora. Orientações para adaptar a escola. Porto Alegre: Artmed; 2004.

19. Braum KVN. Factors associated with leisure activity among young adultus with develop mental disabilities. RIDD-53 I, v. 17, 2005.

20. Mancini MC. Comparação do desempenho de atividades funcionais em crianças com desenvolvimento normal e crianças com paralisia cerebral. Are Neuropsieuiatr 2002; 60(2). 